\title{
DETERMINING FRACTURE TOUGHNESS OF WOOD FLOUR/HEMP-REINFORCED PVC POLYMER COMPOSITES
}

\author{
KRISZTINA ROMÁN, BELLA UDVARDI, EMESE KUROVICS, \\ TAMÁS J. SZABÓ \& KÁLMÁN MAROSSY \\ Institute of Ceramics and Polymer Engineering, University of Miskolc, Hungary
}

\begin{abstract}
Rigid PVC wood flour composites were prepared with various volume fractions of wood flour to investigate the effect of the structure properties on the fractural and tensile behavior. During the mixture preparation the first question is the compatibility of the wood flour additive with the rigid PVC and the safe concentration range of the additive. The second question is the fractural behavior of the composites. Accordingly, the 300-400 micrometer particle size beech wood content was varied using 15, 20, 25 parts per weight of the polymer matrix. Since both the PVC and the major components of the beech wood (cellulose and lignin) are polar, we did not use a coupling agent between the polymer and the natural filler. Thus, the properties of the composites as function of concentration can be examined. The usual mechanical properties, such as tensile strength, elongation at break and so-called compact tensile fracture mechanical analysis was also performed. It has been found that the composites could be safely processed with up to 25 parts by weight wood content. However, the properties of 25 parts by weight filler content sample already showed a decrease in strength properties. We also tried to improve the fracture mechanical properties with fibrous ( $1 \mathrm{~cm}$ long) natural filler. In this case 20 parts by weight of wood flour content with one, three and five parts by weight hemp fiber were used in the PVC polymer matrix. The tests results showed that these fibrous fillers neither decrease nor improve the mechanical properties. The raw measurement results were evaluated according to the critical stress intensity factor $\left(\mathrm{K}_{\mathrm{c}}\right)$ and the critical crack propagation energy $\left(\mathrm{G}_{\mathrm{c}}\right)$. Ultrasound propagation measurements are in progress trying to determine the effect of structural changes and interactions at increased hemp fiber content.
\end{abstract}

Keywords: PVC composite, mechanical properties, $K_{c}, G_{c}, L E F M$.

\section{INTRODUCTION}

Poly (vinyl chloride) polymers are used in a variety of commercial products, such as pipes, windows profiles, cables, rigid sheets, insulators etc., due to their unique properties [1], [2]. Fiber additives are often applied to increase the mechanical strength of the materials. The natural fibers and flours made by grinding have been frequently applied to the polymers [3]. The natural fiber/flour-reinforced composites have attracted the attention of many scientists in the field of composite materials, because they have lot of advantages. These advantages are the lower density, high strength, high modulus and more biodegradable nature [4].

In fracture mechanical tests, the cracking behaviour of polymeric materials can be examined. Researchers reported that the composite's flexibility and strength are influenced by wood quantity and sizes. The high content of wood fillers resulted in poor adhesion between the polymer matrix and the wood filler. Studies have reported that a higher quantity of the filler reduces the impact strength by up to $60 \%$ [5]. To improve the fatigue behaviour of composites and to develop improved materials, it is essential to better understand the fatigue mechanism of unidirectional materials [6]. For investigating in the area of the linear elastic fracture mechanics (LEFM), the phenomenon of fatigue crack propagation analyzed by various analytical methods was evaluated, for example it can determine the $\mathrm{K}_{\mathrm{c}}$ critical stress intensity factor [7]. 
The science of fracture mechanics has increasingly influenced the design and experimental work, which includes the prediction of lifetime of the products. However, the mathematical and physical models generally focus on a one axis stress crack area [8]. The time-dependent properties of the composite materials are very important, especially creep, stress relaxation and fatigue investigations. It was found that the rate of creep decreased with the wood content. The other parameter modifying the fatigue process is moisture. The moisture greatly influences the time-dependent properties of PVC composites, because the wood and also the hemp has hydrophilic nature [9].

According to recent literature, tests under cyclic loading are very rarely used. However, this type of investigations on building materials is very useful, in particular on products exposed to earthquakes or pedestrian bridges [10]. For testing fatigue, there exists a method, which examines the acceleration of fracture. Several studies deal with the nature of the spread of fatigue cracking in PVC. The change of the length of crack is expressed as a change in the cycle in the $\mathrm{da} / \mathrm{dN}-\Delta \mathrm{K}$ period, which is usually described by the traditional Paris relation. The process is highly dependent on the composition; e.g. the molecular weight of the matrix polymer or the plasticizer content and type if used. It has been observed that the crack growth was reduced when the $\mathrm{da} / \mathrm{dN}-\Delta \mathrm{K}$ period was decreased [11].

Fracture parameters are also tested using the three-point bending test based on the Jeng and Shah models [12]. The easiest way to analyze the fracture behaviour is to use Wöhler's rotating bending test for polymer materials. It is one of the most commonly used method for comparing the fatigue life expectancy of different materials. For thermoplastics the fatigue failure studies were originally based on the traditional technique of empirical analysis of metals [8].

\section{THEORY}

The fatigue is usually the most common structural failure of polymers; this problem is caused by cyclic or random loads. Fatigue failure begins with the formation of cracks in high stress regions [13]. Fig. 1 shows the flow chart of the fracture mechanism and the route of evaluation.

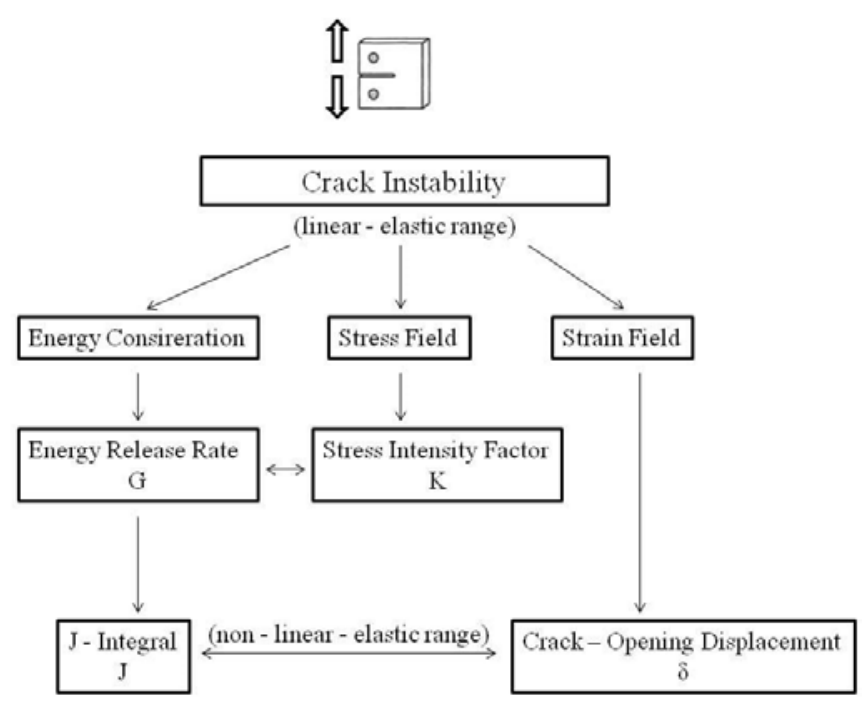

Figure 1: Outline of the fracture mechanism [14]. 
The tensile stress gradually increases during the linear fracture test while the size of the crack begins to increase in the specimens then the force is reduced. The intensity factors $\mathrm{K}_{\mathrm{c}}$ give the stress-dependent term [14]

$$
\mathrm{K}_{\mathrm{c}}=\sigma_{\mathrm{i}} \sqrt{\mathrm{a}},
$$

where $\sigma_{\mathrm{i}}=$ external stress, $\mathrm{a}=$ distance between the fixing and bottom of the notch $(\mathrm{m})$. Since these values are evaluated by using finite samples, geometric factors (f) must be included, which leads to the final equations [14]

$$
\mathrm{K}_{\mathrm{c}}=\mathrm{f} \frac{\mathrm{F}_{\max }}{\mathrm{B} \mathrm{w}^{1 / 2}}[\mathrm{~N} / \mathrm{m}]
$$

where $\mathrm{f}=$ geometric factor, $\mathrm{F}_{\max }=\operatorname{maximum} \operatorname{load}(\mathrm{N}), \mathrm{B}=$ thickness $(\mathrm{m}), \mathrm{W}=$ width $(\mathrm{m})$. The values of the " $\mathrm{f}$ " were determined from the geometry of the specimens.

We used critical crack propagation energy $\left(G_{c}\right)$ to describe the instability of cracks material by stress and energy [14]

$$
\mathrm{G}_{\mathrm{c}}=\frac{\mathrm{U}}{\mathrm{BW}_{\varphi}}\left[\mathrm{J} / \mathrm{m}^{2}\right]
$$

where $\mathrm{U}=$ deformation energy $(\mathrm{Nm}), \mathrm{W}=$ width of the sample $(\mathrm{m}), \varphi=$ geometrical factor.

\section{MATERIALS AND SAMPLES PREPARATION}

\subsection{Materials}

The polymer matrix was poly (vinyl chloride) $(\mathrm{PVC})$ of $\mathrm{K}$ value $=58$. The wood flour was made of beech, with a particle size between 300 to 400 micrometers. The fiber size of the hemp is about $10 \mathrm{~mm}$. All of the natural raw materials were purchased from a wholesaler in Hungary. The formulation contained the usual additives being necessary for PVC processing: $\mathrm{Ca}-\mathrm{Zn}$ based stabilizer, paraffin based external, partial glycerol ester type internal lubricants, ground $\mathrm{CaCO}_{3}$ filler and acrylic based processing aid.

\subsection{Sample preparation}

In the preparation of starting mixtures, first PVC powder and processing additive were added and mixed manually. This mixture was the reference of the measurement (its ID number is O-1). The other three mixtures contain different amounts of wood flour. The first composite mixtures contain 15 weight ratio of wood next to PVC. The second contain 20 and the last 25 weight ratio of wood. They will be referred to in the following line: $\mathrm{C}-1, \mathrm{C}-2, \mathrm{C}-3$. The last three composites also contain hemp fibers next to $20 \mathrm{phr}$ wood and PVC. The amount of their application: 1, 3, 5 weight part per 100 PVC. Then they were referred to in the following: $\mathrm{CH}-1, \mathrm{CH}-2, \mathrm{CH}-3$.

The powder mixtures were roll milled at $170^{\circ} \mathrm{C}$ on at twin roll mill Schwabenthan $150 \mathrm{UL}$ electrical heated roll mill. The roll milled felts were compression moulded at $175^{\circ} \mathrm{C}$ about 100 bar pressure into 1 and $4 \mathrm{~mm}$ thick plates. Tests specimens were machined from these plates for the compact tensile tests: the specimens had nominal dimensions of $35 \mathrm{~mm}$ length, $5 \mathrm{~mm}$ thickness, $30 \mathrm{~mm}$ width (measuring parameter) and holes $5 \mathrm{~mm}$ diameter. 


\section{EXPERIMENTS AND METHODS}

\subsection{Determination of density, hardness, fracture and tensile mechanical tests}

The density values were determined by Archimedes principle weight measurement in water. The hardness tests were carried out with a Zwich/Roell machine using Shore D duromer punching tool. The density and hardness values of the mixtures are shown in Table 1.

Table 1: Density and hardness measurement of PVC composites.

\begin{tabular}{|l|c|c|c|c|c|c|c|}
\hline & \multicolumn{7}{|c|}{ Materials } \\
\cline { 2 - 8 } & $\mathrm{O}-1$ & $\mathrm{C}-1$ & $\mathrm{C}-2$ & $\mathrm{C}-3$ & $\mathrm{CH}-1$ & $\mathrm{CH}-2$ & $\mathrm{CH}-3$ \\
\hline Density $\left(\mathrm{g} / \mathrm{cm}^{3}\right)$ & 1.41 & 1.42 & 1.40 & 1.42 & 1.42 & 1.43 & 1.43 \\
\hline Hardness (Shore D) & $81 \pm 0.1$ & $82 \pm 0.6$ & $81 \pm 0.3$ & $83 \pm 0.4$ & $81 \pm 0.7$ & $82 \pm 0.5$ & $81 \pm 0.8$ \\
\hline
\end{tabular}

For fracture mechanics tests on polymers CT specimens are frequently used. The incision of the fracture mechanical specimen was further increased and sharpened with a blade, with which the front position of the initial crack can be fixed. After, these specimens were subjected to tensile stress. From the results of the tensile test the conventional fracture toughness $\left(\mathrm{K}_{\mathrm{Q}}\right)$ can be determined. The conventional fracture toughness load parameters are the $\mathrm{F}_{\mathrm{Q}}$ load at when the crack is starting. Fig. 2 illustrates the integral of force versus deformation curve and $\mathrm{F}_{\max }$ value.

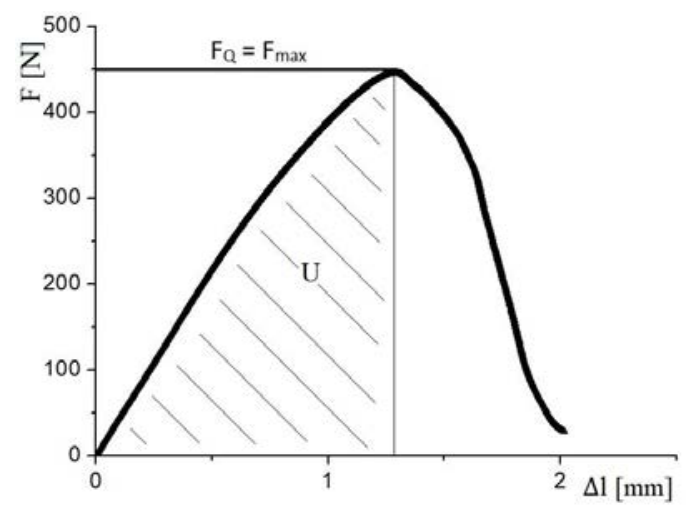

Figure 2: Evaluation of the tensile curves.

$U$ is the integral of force until $F_{\max }$ i.e. the area under the curve from zero to $F_{\max }$. The $G_{c}$ values can be determined with the value of the energy associated with residual deformation.

According to the preliminary experiments, $\mathrm{F}_{\mathrm{Q}}=\mathrm{F}_{\max }$ was used as a critical break force to determine the fracture toughness. The final measurement results were determined from the average of five measurements. The tests were performed on INSTRON 5566 universal testing machine at room temperature $\left(23 \pm 1^{\circ} \mathrm{C}\right)$. The cross-head speed was $10 \mathrm{~mm} / \mathrm{min}$.

The tensile tests were carried out with the same universal INSTRON 5566 machine at room temperature $\left(23 \pm 1^{\circ} \mathrm{C}\right)$. The cross-head speed was $50 \mathrm{~mm} / \mathrm{min}$. When force-elongation data are converted to engineering stress and strain from the test results, a stress-strain curve that is identical in shape to the force-elongation curve can be plotted. 


\section{RESULTS AND DISCUSSION}

The density values only slightly change regardless of the amount of wood flour and hemp fiber used. This is also experienced with the results of hardness tests. It is not surprising because the compact density both of the wood and the hemp fiber is about $1.5 \mathrm{~g} / \mathrm{cm}^{3}$ near to the density of matrix material.

It appears in Table 2 that the tensile strength is improved by the effect of hemp fiber and wood flour relative to the original PVC sample. However, the hemp fiber used as an additional reinforcement compared to the wood flour does not change the tensile strength values significantly compared to the $15 \mathrm{phr}$ wood flour samples. The wood flour is micro fibrous filler so it has similar effects as hemps which are a long fibre compared to the flour. It is visible that using more than $15 \mathrm{phr}$ wood flour start to weaken the composite as the interaction between the matrix and the filler is getting saturated. It is interesting that by using long fiber hemp we can improve the mechanical properties back to the $15 \mathrm{phr}$ wood flour sample.

Table 2: Results of the tensile tests.

\begin{tabular}{|l|c|c|c|c|c|c|c|}
\hline & \multicolumn{7}{|c|}{ Materials } \\
\cline { 2 - 8 } & $\mathrm{O}-1$ & $\mathrm{C}-1$ & $\mathrm{C}-2$ & $\mathrm{C}-3$ & $\mathrm{CH}-1$ & $\mathrm{CH}-2$ & $\mathrm{CH}-3$ \\
\hline $\begin{array}{l}\text { Tensile strength } \\
(\mathrm{MPa})\end{array}$ & $37.5 \pm 1.5$ & $45 \pm 1.1$ & $42 \pm 0.9$ & $35.1 \pm 0.5$ & $37.5 \pm 2.0$ & $42.6 \pm 1.0$ & $44.8 \pm 0.4$ \\
\hline
\end{tabular}

The higher the values of $\mathrm{K}_{\mathrm{c}}$ and $\mathrm{G}_{\mathrm{c}}$ in fracture tests, the more resistant is the material against crack propagation. Table 3 shows the critical stress intensity factor and the critical crack propagation energy values of the specimens. It is supposed that wettability of the wood flour and the hemp is not enough to obtain a good reinforcing effect; using a coupling agent would be advantageous.

Table 3: Results of the tensile test of the all materials.

\begin{tabular}{|c|c|c|c|c|c|c|c|}
\hline \multirow{2}{*}{} & \multicolumn{7}{|c|}{ Materials } \\
\cline { 2 - 8 } & $\mathrm{O}-1$ & $\mathrm{C}-1$ & $\mathrm{C}-2$ & $\mathrm{C}-3$ & $\mathrm{CH}-1$ & $\mathrm{CH}-2$ & $\mathrm{CH}-3$ \\
\hline $\mathrm{K}_{\mathrm{c}}$ & $2.4 \pm 0.1$ & $2.5 \pm 1.1$ & $2.9 \pm 0.1$ & $2.4 \pm 0.0$ & $2.8 \pm 0.2$ & $2.6 \pm 0.2$ & $2.6 \pm 0.2$ \\
\hline $\mathrm{G}_{\mathrm{c}}$ & $11.8 \pm 2.0$ & $7.5 \pm 0.9$ & $8.7 \pm 1.3$ & $7.2 \pm 0.8$ & $6.9 \pm 0.7$ & $5.9 \pm 0.7$ & $6.4 \pm 1.0$ \\
\hline
\end{tabular}

No significant changes in the $\mathrm{K}_{\mathrm{c}}$ values can be detected if the scatter values are taken into account. In contrast $\mathrm{G}_{\mathrm{c}}$ values have visible changes. Forming a heterogeneous phase when using fiber and flour filler, can cause the structural deterioration. Fig. 3 shows $K_{c}$ and $G_{c}$ values with scatters. Since the values of $G_{c}$ depends on the modulus of elasticity and maximum force, so the deformability and flexibility of the materials will also affect the crack propagation energy values.

Fig. 4 shows the process of propagation of crack. The second image of Fig. 4 shows the crack at the time of the maximum force values. Subsequently decreasing force was observed when the crack has grown. 


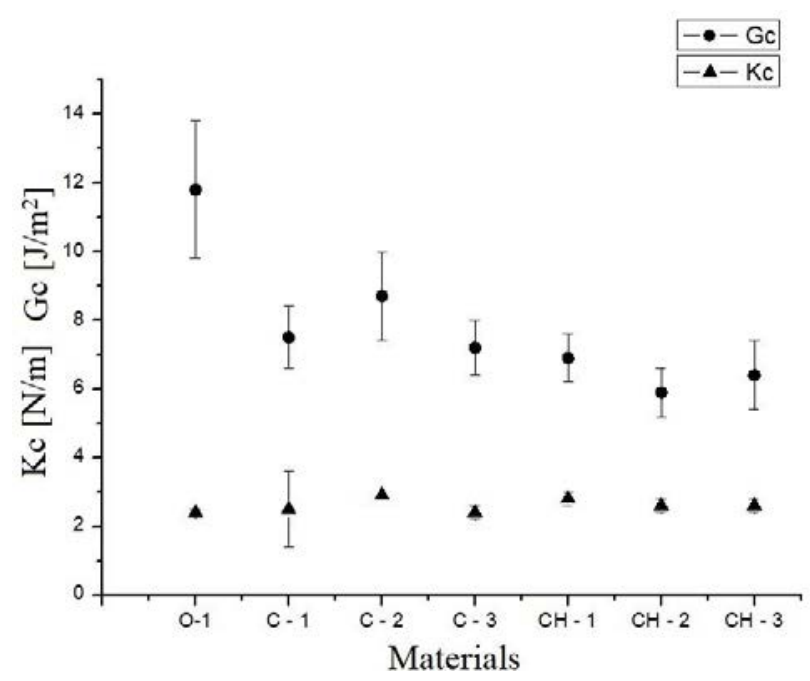

Figure 3: $\mathrm{K}_{\mathrm{c}}$ and $\mathrm{G}_{\mathrm{c}}$ values are the all samples.

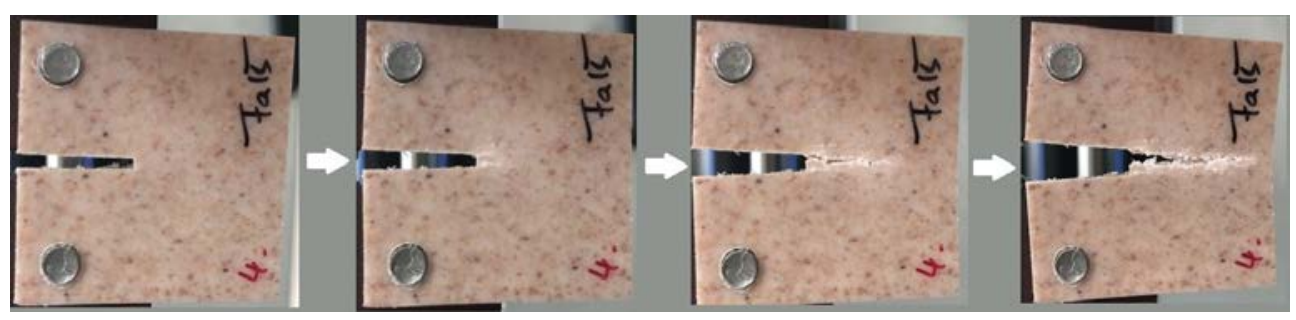

Figure 4: Measurement process for the fractural test.

\section{CONCLUSION}

The purpose of the fracture mechanics is to develop methods for characterizing the initial instability of microscopic cracks. Within the linear fracture mechanical test, the critical stress intensity factor and critical crack propagation energy have been shown to be suitable for characterization of the cracking process. The fracture toughness of PVC composites is hardly affected by the presence of additive. Only a small decrease in the fracture toughness was observed relative to the fracture toughness of the origin sample. The wood and hemp fillers leads to an increase of the craze dimension and decrease the loading capacity of the craze. The small variation in the $\mathrm{G}_{\mathrm{c}}$ and $\mathrm{K}_{\mathrm{c}}$ fracture parameters observed for PVC suggests that the amount of fillers gives almost balanced results. Therefore we continue the research with selected coupling agents.

\section{ACKNOWLEDGEMENTS}

The described article/presentation/study was carried out as part of the EFOP-3.6.1-16-00011 "Younger and Renewing University - Innovative Knowledge City - institutional development of the University of Miskolc aiming at intelligent specialisation" project implemented in the framework of the Szechenyi 2020 program. The realization of this project is supported by the European Union, co-financed by the European Social Fund. This research 
was supported by the European Union ant the Hungarian State, co-financed by the European Regional Development Fund in the framework of the GINOP - 2.3.4.-15-2016-00004 project, aimed to promote the cooperation between the higher education and the industry.

\section{REFERENCES}

[1] Titow, W.V., PVC Technology, 4th ed., Elsevier Applies Science Publishers: London and New York, 1984.

[2] Lee, J., Moon, J., Lee, H. \& Choi, B., Investigation of fatigue and mechanical properties of the pipe grade poly (vinyl chloride) using recycled scraps. eXPRESS Polymer Letters, 9(4), pp. 362-371, 2015.

[3] John K. \& Naidu, S.V., Tensile properties of unsaturated polyester-based sisal fiberglass fiber hybrid composites. Journal of Reinforced Plastics and Composites, 23(17), pp. 1815-1819, 2004.

[4] Takagi, H., Nakagaito, A.N., Nishimura, K. \& Matsui, T., Mechanical characterisation of nanocellulose composites after structural modification. WIT Transactions on the Built Environment, vol. 166, WIT Press: Southampton and Boston, pp. 335-341, 2016.

[5] Jiang, H. \& Kamdem, D.P., Mechanical properties of poly (vinyl chloride)/wood flour/glass fiber hybrid composites. Journal of Vinyl and Additive Technology, 9(3), pp. 138-145, 2003.

[6] Curtis, P.T., Tensile fatigue mechanisms in unidirectional polymer matrix composite materials. International Journal of Fatique, 13(5), pp. 377-382, 1991.

[7] Radon, J.C., Physics fatigue of polymers: Crack growth in PVC. Journal of Macromolecular Science, Part B Physics, 14(4), pp. 37-41, 2006.

[8] Leevers, P.S., Culver, L.E. \& Radon, J.C., Fatigue crack growth in PMMA and rigid PVC under biaxial stress. Engineering Fracture Mechanics, 11(3), pp. 487-498, 1979.

[9] Breen, J., Environmental stress cracking of PVC and PVC-CPE - Part I Crazing, Journal of Materials Science, 28(14), pp. 3769-3776, 1993.

[10] Pulngern, T. et al., Effects of cross-section design and loading direction on the creep and fatigue properties of wood/PVC composite beams. Journal of Vinyl and Additive Thechnology, 16, 2010.

[11] Hu, Y. \& Summers, J., Correlation of fatigue and creep crack growth in poly (vinyl chloride). Journal of Materials Science, 38, pp. 633-642, 2003.

[12] Xu, S. \& Reinhardt, H.W., Determination of double-K criterion for crack propagation in quasi-brittle fracture. Part II: Analytical evaluating and practical measuring methods for three-point bending notched beams. International Journal of Fracture, 98, pp. 151177, 1999.

[13] Radon, J.C., Fatigue crack growth in polymers. International Journal of Fracture, 16(6), pp. 533-552, 1980.

[14] Ramsteiner, F., Schuster, W. \& Forster, S., Concepts of fracture mechanics for polymers. Deformation and Fracture Behaviour of Polymers, pp. 27-50, 2001. 